\title{
Os modelos na ciência: traços da evolução histórico-epistemológica
}

\author{
Models in science: traces of historical-epistemological evolution \\ Fernando Siqueira da Silva*1@, Francisco Catelli2 \\ ${ }^{1}$ Universidade Federal do Pampa, São Borja, RS, Brasil \\ ${ }^{2}$ Universidade de Caxias do Sul, Caxias do Sul, RS, Brasil
}

Recebido em 07 de Fevereiro de 2019. Revisado em 28 de Março de 2019. Aceito em 06 de Maio de 2019

O que é um modelo? Neste artigo apresentamos alguns aspectos históricos e epistemológicos da noção de modelo desde sua inserção na ciência até a sua concepção mais contemporânea. O cenário é limitado às ciências formais e factuais. Analisando algumas discussões entre filósofos da ciência e cientistas, a respeito das diferentes noções de modelo, partimos do final do século XIX onde aparecem os modelos mecânicos e as analogias em física (1860), passamos pelos modelos em lógica matemática (1920), depois pelos modelos matemáticos, objetos-modelos e seus modelos teóricos (1950) e chegamos à metade final do século XX onde aparecem os modelos computacionais (1980). Percebe-se então que a resposta à pergunta "o que é um modelo?" não pode ser dada de modo universal. Um desenho, um diagrama, um esboço, uma ilustração, um objeto concreto (maquete), uma estrutura matemática (modelo simbólico), um software de computador, uma cópia de alguma coisa (modelo icônico), tudo isso pode ser considerado modelo de algo. Tomados no sentido epistemológico todos podem ser considerados como estruturas concretas ou abstratas que visam de alguma forma representar diferentes aspectos de uma determinada realidade, coisa, fato ou fenômeno.

Palavras-chave: Modelos, epistemologia, filosofia da ciência, história da ciência.

What is a model? In this article we present some historical and epistemological aspects of the notion of model from its insertion in science to its more contemporary conception. The scenario is limited to formal and factual sciences. Analyzing some discussions between philosophers of science and scientists, regarding the different notions of model, we start from the end of the 19th century when mechanical models and analogies in physics appear (1860), we go through the models in mathematical logic (1920), then by mathematical models, object-models and their theoretical models (1950) and we arrive at the end half of the 20th century when the computational models appear (1980). It is then realized that the answer to the question "what is a model?" cannot be given universally. A drawing, a diagram, a sketch, an illustration, a concrete object (mockup), a mathematical structure (symbolic model), a computer software, a copy of something (iconic model), all this can be considered a model of something. Taken in the epistemological sense, all can be considered as concrete or abstract structures that aim in some way to represent different aspects of a certain reality, thing, fact or phenomenon.

Keywords: Models, epistemology, philosophy of science, history of science.

\section{Introdução}

Ao escutarmos a palavra "modelo" inevitavelmente logo pensamos na multiplicidade de sentidos em que ela pode ser empregada. A palavra ou termo modelo pode ser utilizada no sentido metafísico, estético, ético, epistemológico adquirindo assim diferentes significados [1].

Neste artigo interessa-nos o sentido epistemológico do conceito de modelo, o qual possui uma evolução histórica que nos parece girar em torno de dois sentidos mais usuais: o modelo como uma representação de algo préexistente de um lado e de um modelo como representação simplificada, abstrata e idealizada da realidade, de outro lado.

*Endereço de correspondência: fernandosiqueiradasilva@gmail.com
Inicialmente, apresentamos alguns aspectos históricos e epistemológicos da noção de modelo na ciência, desde o seu primeiro aparecimento, e por fim algumas considerações entre filósofos da ciência e cientistas quanto aos seus usos e limitações na investigação científica. O espaço temporal escolhido está limitado ao intervalo que vai do final do século XIX ao final do século XX, onde alguns traços da noção de modelo, no corpo das ciências formais (matemática e lógica) e das ciências factuais (física, química, biologia), podem ser percebidos.

Acreditamos que as contribuições sobre a noção de modelo e suas utilizações na ciência seja um assunto central a ser trabalhado entre alunos e professores no ensino de ciências, uma vez que os modelos embora estejam presentes nos materiais de ensino, em formas de objetos tridimensionais, didaticamente transpostos, eles podem 
fornecer distorções sobre a realidade dos fenômenos que tentam representar. Representações estas que auxiliam a nossa compreensão e razão, mas não devem ser confundidas com a realidade dos objetos em si, da qual muitas vezes são meras simplificações e aproximações. Assim, compete ao professor e aos seus alunos terem presente a noção de modelo como uma representação idealizada da realidade, onde as explicações e previsões geradas são no máximo aproximativas e em certos casos, apenas especulativas. Discussões sobre o processo de transposição didática que se inicia na concepção e construção dos modelos científicos, representações idealizadas ou analógicas da realidade, no crivo da ciência, antes de se tornarem modelos didáticos, tem sido o trabalho de alguns professores que se utilizam da modelização em suas atividades 1

\section{A inserção da noção de modelo na ciência: o modelo mecânico e as analogias em física}

A origem etimológica da palavra modelo vem inicialmente do latim modulus que significava "a medida arbitrária utilizada para determinar relatórios de proporção entre as partes de uma obra de arquitetura". Aparece depois, na idade média, no francês como moule (molde), no inglês como mould e no alemão como mold. Encontrase também, durante o período Renascentista Italiano, entre os séculos XIV e XVI, modello, que em francês tornava-se modèle, em inglês model e em alemão modell [5]. Essas transformações da noção de modelo, que antes era utilizada por artesãos, pedreiros e arquitetos aos poucos foram sendo incorporadas à área científica, com uma consequente adaptação de seus significados, como será visto a seguir.

Há indícios de que apenas em meados do século XIX a noção de modelo surge no debate científico. Embora seu uso seja um pouco anterior, remontando ao século XVIII, quando era utilizado pelos astrônomos como sinônimo de sistema [6] [7]. Entretanto, sua entrada enquanto elemento epistemológico deu-se um pouco mais tarde. Falar sobre modelos em física antes de 1860, em matemática antes de 1900 e em ciências sociais antes de 1920 seria cometer uma espécie de anacronismo de vocabulário, já que "nem Pascal, nem Descartes, nem Newton, nem Laplace falam de modelização para descrever o que eles fazem" [5, p.93].

É com Suzanne Bachellard (1983) que se deu o resgate do que pode ser a origem da noção de modelo no debate científico, ao mencionar um artigo publicado pelo físico austríaco Ludwig Edward Boltzmann (1844 - 1906) em 1902, na décima segunda edição da enciclopédia britânica, intitulado "Model" [5][6][8]. Partindo inicialmente das áreas artísticas e técnicas, a noção de modelo emerge

\footnotetext{
1 Para saber mais sobre as especificidades dos modelos científicos e dos modelos didáticos [2]; e algumas atividades de epistemologia prática da modelização em Educação em Astronomia [3][4].
}

na investigação científica e no corpo das ciências físicas, mecânicas e matemáticas como "representação tangível [...] de um objeto que tem uma existência real ou é uma construção factual ou mental" [5, p.94]:

"Há muito tempo os filósofos perceberam a essência do nosso processo de pensamento no fato de que nós ligamos aos objetos reais em torno de nós atributos físicos particulares nossos conceitos - e por meio desses tentamos sinalizar esses objetos ao nosso espírito. Tais opiniões foram no passado consideradas por matemáticos e físicos, como nada mais do que especulações inférteis, mas elas foram recentemente intimamente associadas por Maxwell, Helmholtz, Mach, Hertz, e muitos outros ao corpo inteiro da teoria matemática e física. De acordo com estes pontos de vista, nossos pensamentos estão para as coisas na mesma relação que os modelos estão para os objetos que eles representam. A essência do processo é a fixação de um conceito com um conteúdo definido para cada coisa, mas sem implicar numa completa semelhança entre coisa e pensamento; pois naturalmente não sabemos quase nada sobre a semelhança entre nossas ideias e as coisas às quais nós as ligamos. O que é essa semelhança repousa principalmente sobre a natureza da ligação, a correlação sendo análoga aquela que obtemos entre pensamento e linguagem, entre linguagem e escrita, entre sons musicais e notas sobre a pauta, etc." (Boltzmann, 1902, grifo nosso).

De fato, esta parecia ser a noção predominante na investigação científica entre a metade final do século XIX e o início do século XX; é o denominado "modelo mecânico", entendido como representações de objetos reais (concretos) ou mentais (abstratos) para a compreensão dos fenômenos naturais ou físicos [5][6]. Comenta-se que essa acepção de modelo estava presente em muitos dos trabalhos de Boltzmann, nos quais as propriedades macroscópicas da matéria eram compreendidas através de suas propriedades microscópicas com auxílio de conceitos da mecânica: "esta sua predileção por modelos mecânicos, que inclusive o aproximou de Maxwell, foi a espinha dorsal do seu modus operandi e colocou-o posteriormente em rota de colisão com grandes cientistas da sua época" $[9] 2$.

$\mathrm{O}$ desenvolvimento desse tipo de modelo no ambiente experimental dos laboratórios, relacionando objetos reais (maquetes de madeira, metal ou papelão) e objetos mentais (equações matemáticas) para o estudo do movimento

\footnotetext{
2 Alguns físicos dessa época, como Wilhelm Ostwald (1853-1932), Georg Helm (1851-1923) e Ernst Mach (1838-1916) questionavam a falta de significado nas analogias empregadas por Boltzmann [9, p.21].
} 
dos gases, dos elétrons, entre outros, ocorria geralmente através do emprego das analogias. Boltzmann valia-se ao mesmo tempo de um "transporte analógico e de um suporte matemático que permite identificar a analogia estrutural [ou substancial] e de automatizar este transporte. Temos ai uma condição forte da noção de modelo, conceito que a distingue de uma simples matematização" $[5$, p.95].

Ao contrário de alguns cientistas de sua época que apresentavam uma preocupação lógica quase que obsessiva na constituição de seus modelos, Boltzmann via uma "continuidade entre os modelos materiais e os modelos matemáticos" [5, p.95], embora sua atenção estivesse realmente dirigida ao nível conceitual dessas formas de representação.

Essa relação de transporte analógico entre modelos materiais (maquetes) e modelos matemáticos (equações) como auxiliares na construção de algumas teorias físicas era também empregada de modo semelhante pelo físico e matemático James Clerk Maxwell (1831-1879) ${ }^{3}$ o qual fazia o uso de dois tipos gerais de analogias. Trata-se das analogias substanciais e das analogias formais.

"Nas analogias do primeiro tipo [ou substanciais], supõe-se que um sistema de elementos que possui certas propriedades já conhecidas, que se supõe estarem relacionadas das maneiras conhecidas como enunciadas em um conjunto de leis do sistema, é um modelo para a construção de uma teoria em relação a um segundo sistema. No segundo ou no tipo formal de analogia, o sistema que serve de modelo para construir uma teoria é alguma estrutura conhecida de relações abstratas, em vez de ser, como nas analogias substantivas, um conjunto de elementos mais ou menos visualizáveis que se correlacionam mutuamente em relações conhecidas" [11].

Um exemplo de analogias substanciais pode ser encontrado na teoria cinética dos gases, onde as moléculas seriam representadas por pequenas esferas rígidas em permanente movimento caótico. Para as analogias formais a nova noção de massa que emerge da teoria da relatividade é um exemplo de como o formalismo matemático da mecânica clássica foi usado como modelo para a ereção de uma nova teoria.

As analogias substanciais teriam na ciência, segundo Hempel [11, p.212] um valor heurístico ou didático, permitindo a busca de uma similaridade entre coisas, elementos, objetos distintos ao nível do material (do concreto, do tangível) enquanto as analogias formais, segundo Dutra $[11$, p.212] estariam mais bem relacionadas a uma similaridade ao nível do conceitual (do abstrato, do intangível).

\footnotetext{
3 Maxwell e Boltzmann foram contemporâneos e contribuíram decisivamente para o desenvolvimento da termodinâmica.

Um estudo mais específico sobre as noções de modelo e analogia, empregadas pelos físicos acima mencionados, merece destaque [10].
}

Segundo o econometrista Michel Armatte [5, p. 967] por algum tempo viu-se o domínio das analogias no desenvolvimento dos modelos mecânicos (científicos) para a constituição das teorias em física, em especial nas primeiras duas décadas do século XX, onde elas tomaram uma "posição central e irreversível [...]", em especial as analogias do tipo formal (essencialmente matemáticas) que, a partir de 1920, passariam a caracterizar os modelos da lógica matemática 4

\section{A noção de modelo em lógica matemática: abordagem semântica}

Uma nova noção de modelo científico começa a se desenvolver em meados de 1920 e se estenderá até por volta de 1970; essa noção renovada nutre-se predominantemente da abordagem semântica, no interior da lógica matemática [13].

Em um breve resgate histórico, os econometristas aludem aos vários acontecimentos que se sucederam até o seu primeiro desenvolvimento. Seus traços são oriundos da tentativa de matemáticos, lógicos e filósofos em criar uma base unitária, segura e precisa, inicialmente, para as matemáticas: geometria, álgebra, análise, aritmética que estariam entre o primeiro quarto do século XIX e início do século XX com problemas internos em seus fundamentos. E, posteriormente, essa base seria estendida para toda a ciência em desenvolviment ${ }^{5}$

Segundo o filósofo da ciência Luiz Henrique de Araújo Dutra [11][15] alguns cientistas e filósofos da ciência que defendem a abordagem semântica (entre eles, Frederick Suppe, 1977 e Bas van Frassen, 1980) sustentam que as teorias científicas devem ser interpretadas como "coleções ou famílias de modelos". Para Van Frassen, essas coleções ou famílias de modelos são basicamente representações de objetos matemáticos também denominados por ele de "semânticos" ou "metamatemáticos", usualmente "[...] utilizados pelos lógicos na interpretação, por exemplo, de linguagens de primeira ordem" [...], o que se costuma denominar de modelo matemático" [11, p.205]. O modelo matemático na abordagem semântica é utilizado pelos lógicos para julgar se os teoremas que emergem de uma determinada teoria são verdadeiros ou falsos, aponta. Estes cientístas e filósofos da ciência, de modo geral (exceto Van Frassem) fazem uso de uma estrutura formal oriunda da teoria dos conjuntos:

\footnotetext{
${ }^{4}$ Uma forma interessante de entendermos esses dois tipos de analogias para a constituição dos modelos e suas possíveis utilizações na busca por uma similaridade entre objetos distintos, pode ser encontrada no livro "Teoria e Realidade" do filósofo da ciência Mário Bunge (1974, p. 185-189) [12].

5 Retomar todo esse contexto de crise nas matemáticas bem como buscar todas as suas causas seria um projeto extenso e complexo, que evitamos aqui; concentrar-nos-emos na noção do modelo ela mesma. Um estudo interessante sobre esse momento tenso na filosofia da matemática pode ser encontrado em [14].
} 
"Trata-se, neste caso, de uma estrutura composta do par ordenado $<\mathrm{U}, \mathrm{I}\rangle$, sendo que U é uma coleção de indivíduos dos quais falamos, e I é uma função interpretação, que dá nomes aos indivíduos de $\mathrm{U}$, e especifica a extensão dos predicados e relações pertencentes à linguagem de primeira ordem na qual a teoria é formulada, tal como o tema é explicado nos livros de lógica elementar" [11, p. $215]$.

Essa noção de modelo semântico, formalizada e logicisada, assume uma posição central na lógica matemática, permitindo importantes avanços na própria matemática e em outros campos do conhecimento (especialmente nas engenharias) estendendo-se até meados de 1970, ocasião em que, a partir da cada vez extensa utilização dos computadores e da informática, essa forma de modelagem (ou modelização) passa a perder seu espaço para a simulação $[13]$.

\section{Os modelos no pós-guerra: modelo matemático, objetos-modelo e modelo teórico}

O emprego da linguagem matemática em várias áreas do conhecimento adquiriu sua hegemonia numa época em que os homens gostariam de não mais recordar. Foi com o advento da Segunda Guerra mundial que, de acordo com o filósofo da ciência Mário Bunge, o desenvolvimento de pesquisas em inúmeras áreas do conhecimento não-físico (psicologia, sociologia, medicina, economia, entre outras) passou a se dar através da construção de metodologias e teorias por meio da utilização dos modelos matemáticos [12]. Isso levou o autor afirmar que:

"[a] ciência contemporânea não é apenas experiência planificada, executada e entendida a luz de teorias. Tais teorias apresentam-se muitas vezes envoltas em linguagem matemática: toda teoria especifica é, na verdade, um modelo matemático de um pedaço da realidade" [12, p.10].

Foi neste período tenso da história da humanidade que muitos matemáticos de países sob a tutela da Alemanha foram expatriados; muitos deles acabaram aportando na América, em especial nos Estados Unidos [16] onde se encontraram com outros matemáticos, físicos, biólogos, engenheiros, psicólogos, e outros profissionais, originandose daí um grande número de grupos de pesquisa universitária com tendência interdisciplinar, muitos deles a serviço das indústrias e do desenvolvimento militar norte Americano [12] [5].

A partir desse momento se deu um grande avanço no desenvolvimento de novas áreas da matemática, principalmente no setor da matemática aplicada, entre elas, "A álgebra dos grupos, a teoria dos jogos, teoria das preferências, a programação linear, a programação dinâmica, a teoria dos grafos, os testes sequenciais [...]" [5, p.112], o que permitiu de igual modo, o nascimento de outras disciplinas e muitas outras teorias, entre elas: "a teoria geral dos sistemas, a cibernética, a teoria da informação, [...] a sociologia matemática [...] a lingüistica matemática [...] a biologia matemática e a psicologia matemática" $[12$, p.12].

As matemáticas aplicadas se caracterizam então pela aplicação dos objetos matemáticos ao estudo e desenvolvimento de outras áreas do conhecimento, sejam elas de ciência básica, tecnológicas ou industriais. Elas geralmente fazem uso de um processo chamado de modelagem matemática que "transforma uma situação/questão escrita na linguagem corrente e/ou proposta pela realidade, em linguagem simbólica da matemática [...]" [17]. Essa linguagem simbólica e todas as suas relações possíveis constituem-se nos modelos matemáticos [18] utilizados para descrever e explicar essa situação ou questão. No entanto, é preciso ter claro que nem todo modelo matemático deve ser entendido como modelo no sentido semântico da lógica matemática, isto é, nem todo o modelo matemático está atrelado a um sistema formal conjuntista tal como apresentado anteriormente.

O emprego dos modelos matemáticos para a resolução dos problemas científicos e para a construção das teorias científicas surgiu como uma forma de trazer mais precisão e clareza para muitas teorias de outras áreas que faziam uso quase que exclusivo da estatística nesse empreendimento, procurando mais a acumulação de dados ou fatos do que realmente buscando a sua compreensão [12].

Essa "revolução científica" ocorrida a partir de 1950, não implicou numa "[...] substituição de uma teoria científica por outra [é muito mais] o esforço de teorização em campos até então não-teóricos" [12, p.13]. Tratou-se do uso de uma nova metodologia que há muito tempo fora monopolizada pela física e que passa agora a ser aplicada a outros ramos da ciência. Nessa nova abordagem predomina o método hipotético-dedutivd ${ }^{6}$ e suas características mais marcantes são os "objetos-modelo" e os "modelos teóricos" (esses últimos também denominados por Bunge de "teorias específicas").

\subsection{Os objetos-modelo e seus modelos teóricos: os intermediários entre as teorias gerais e os dados empíricos}

Para Bunge [12] o desenvolvimento conceitual para a compreensão da realidade inicia-se por meio de idealizações e categorizações das coisas ou fatos. Estas idealizações e categorizações somente são possíveis por meio da construção de objetos- modelo ou modelos conceituais dessas

\footnotetext{
6 O método hipotético-dedutivo é apenas um dos muitos caminhos empregados pela ciência para a resolução dos problemas científicos, o qual pode ser compreendido como aquele em que "[...] o cientista, através de uma combinação de observação cuidadosa, hábeis antecipações e intuição científica, alcança um conjunto de postulados que governam os fenômenos pelos quais está interessado, daí deduz ele, as conseqüências por meio da experimentação e, dessa maneira, refuta os postulados, substituindo-os, quando necessário por outros e assim prossegue" [19].
} 
coisas ou fatos. "A formação de cada modelo começa por simplificações, mas a sucessão histórica dos modelos é um progresso de complexidade" [12, p.14]. Ainda segundo o filósofo da ciência, os modelos são construções da observação, da intuição e da razão que, quando submetidos à experiência, podem apresentar tanto suas qualidades quanto seus limites. Seu papel está na tentativa de apreensão da realidade:

\begin{abstract}
"[...] para apreender o real começa-se por afastar-se da informação. Depois, se lhe adicionam elementos imaginários (ou entes hipotéticos), mas com uma intenção realista. Constitui-se assim um objeto-modelo mais ou menos esquemático e que para frutificar deverá ser enxertado sobre uma teoria suscetível de ser confrontada com os fatos" $[12$, p.16].
\end{abstract}

Nessa mesma perspectiva, um objeto-modelo (OM) somente pode ser confiável para determinar algo a respeito de uma determinada realidade (coisa ou fato) se, e somente se, for construída uma teoria específica ou modelo teórico que especifique o comportamento do objeto modelado pelo OM. Desse modo, uma teoria que seja inserida no OM apenas pode ser considerada como modelo teórico de alguma coisa ou fato se, e somente se, especificar as suas peculiaridades. Nesse sentido "[...] um modelo teórico é um sistema hipotético-dedutivo que concerne a um objeto-modelo, que é, por sua vez, uma representação conceitual esquemática de uma coisa ou de uma situação real ou suposta como tal [...]" [12, p.16]. Dito de outra maneira é através do seu modelo-teórico que o objeto-modelo pode, enfim, gerar explicações e previsões da realidade. "Um objeto modelo, portanto, é uma representação de um objeto: ora perceptível, ora imperceptivel, sempre esquemático e, ao menos em parte, convencional" $[12, \mathrm{p} .22]$.

$\mathrm{O}$ autor sustenta que os modelos em geral, ou melhor, os OM, possuem uma relação com as coisas ou fatos, na verdade eles têm a capacidade de representá-los. E essa relação não é biunívoca e sim "multivoca", no sentido em que as relações entre o modelo e a coisa ou entre o modelo e os fatos podem ser inúmeras e vão depender sempre dos meios disponíveis e dos objetivos que se tem. "Um objetomodelo, mesmo engenhoso, servirá para pouca coisa, a menos que seja encaixado em um corpo de ideias no seio do qual se possam estabelecer relações dedutivas" [12, p. 23]. No geral, este corpo de ideias se transforma em um modelo teórico (quando apresentar coerência em relação aos fatos), e quando se refere a um objeto real ou suposto real se transforma em uma teoria específica deste objeto. Porém, um modelo teórico poderá apresentar coerência ou não somente se estiver ancorado por um ou mais aspectos de uma teoria geral.

A epistemologia Bungeana dos modelos tem sido utilizada por alguns renomados pesquisadores [20] [21] que consideram os modelos como os responsáveis por identifi- car as relações entre as "teorias" e os "dados empíricos". Encontrando-se "como intermediários entre as duas instâncias limitrofes do fazer científico: conceitos e medidas" [20, p.15]. Na interpretação do físico e epistemólogo Maurício Pietrocola, Bunge percebe essa necessidade de modelização na ciência como mediadora entre as teorias gerais e os dados empíricos, uma vez que, as primeiras por serem "abstrações produzidas por nossa razão e intuição não se aplicariam a priori às coisas reais". Da mesma forma, "os dados empíricos apesar de mais próximos da realidade, não podem ser inseridos em sistemas lógicos e gerar conhecimento" [20, p.15]. Essa mediação somente é possível por meio da construção de objetos-modelo.

Um apanhado de situações em física que são dessa forma "modelizadas pela ciência" já nos foi exemplificado: $[20$, p.16]

Ao observarmos o Quadro 1, percebemos melhor o que o filósofo da ciência denominou de "objeto-modelo", que pode ser caracterizado como "qualquer representação esquemática de um objeto" [12, p. 32], podendo assim, ter a forma de um desenho (pictórico ou figurativo), de um material concreto (por ex: sólido esférico) ou de uma estrutura conceitual (por ex: onda eletromagnética), embora, segundo o autor, aqueles que realmente interessam para a ciência enquanto construtores e validadores de teorias são os do tipo conceitual:

"[...] as teorias específicas ou modelos teóricos encerram objetos-modelo do tipo conceitual mais do que representações visuais ou figurativas. Sem dúvida, é possível sempre descrever o modelo com o auxílio de um diagrama e mesmo, às vezes, com a ajuda de um modelo material - tais como os modelos esféricos de moléculas: este auxilia a compreender as idéias difíceis e algumas vezes a inventá-las. Não obstante, nem diagramas nem análogos materiais podem representar o objeto de uma maneira tão precisa e completa como o faz um conjunto de enunciados" [12, p. 25-26].

O fato é que a representação por meio de um objetomodelo é sempre parcial, ou dito de outra forma, nem todos os elementos pertencentes à realidade são por ele capturados; e é sempre convencional, isto é, a construção de um objeto-modelo dependerá sempre dos objetivos do modelizador. "A fim de conseguir um modelo teórico, o objeto-modelo tem de ser expandido e engastado em uma moldura teórica. Ao ser absorvido por uma teoria, o objeto-modelo herda as peculiaridades desta e, em particular, suas leis" [12, p. 34]. De modo semelhante, "Todo modelo teórico é parcial e aproximativo: não apreende senão uma parcela das particularidades do objeto representado" [12, p. 30]. Deste modo, pode não sobreviver por muito tempo. Os modelos teóricos, quando não dão mais conta de apreender certos aspectos do objeto representado podem dar origem a novos objetos-modelo e a novas teorias gerais 7

\footnotetext{
7 Porém, os modelos teóricos não devem ser confundidos com os modelos no sentido semântico. Os modelos nesse último sentido devem tornar verdadeiras todas as teorias que se colocam a inter-
} 
Quadro 1: Objetos-modelo: diferentes tipos de representações esquemáticas e suas origens

\begin{tabular}{llll}
\hline SISTEMA & Objeto Modelo & Modelo Teórico & Teoria Geral \\
\hline LUA & Sólido esférico girando em torno do & Teoria Lunar & Mecânica clássica e teoria gravidade \\
& seu eixo & Eletromagnetismo clássico \\
LUAR & Onda eletromagnética polarizada & Equações de Maxwell para o vácuo & plana \\
& Cadeia linear causal de contas & Mecânica estatística de cadeias causais & Mecânica estatística \\
\hline
\end{tabular}
Fonte: adaptado de Pietrocola (1999)

Contudo, Bunge percebe que o emprego dos objetosmodelo e dos seus modelos teóricos "não se mantém nas áreas das ciências em desenvolvimento, onde a construção atua centrifugamente, fora dos objetos-modelo, na maior parte do tempo" [12, p. 36]. Este parece ser o caso de algumas áreas das engenharias e da pesquisa operacional conforme passaremos a discutir.

\section{Os modelos a partir de 1980: os computadores nas simulações de sistemas complexos}

Conforme vimos, a partir dos primeiros trabalhos em lógica matemática, desde 1920 a 1970, todas as noções de modelo na ciência estavam bastante ligadas à "concepção de um modelo que 'representa' um real capturado ao mesmo tempo por uma teoria e por uma observação quantificada" [13, p.244]. De um modelo que servia como instrumento de validação empírica de uma teoria. No entanto, essa concepção a partir de 1980 em algumas áreas da ciência como nas engenharias e na pesquisa operacional não se faz mais de forma predominante 8

Devido à complexidade dos objetos estudados por essas áreas, e as inúmeras variáveis envolvidas, como por exemplo, os problemas da climatologia na previsão do tempo, os novos desafios em medicina, problemas em economia, problemas em logística, em meio ambiente, entre outros, vê-se a ausência de uma teoria completa que dê sustentação para a apreensão da realidade; surge deste modo a necessidade do desenvolvimento de novas teorias e de novos instrumentos. É nesse sentido que se identifica uma nova abordagem de modelo na ciência, ligada ao uso dos computadores nas simulações [5]:

"O modelo torna-se um mecanismo de integração de dados produzidos por um sistema de informação. O modelo, conjuntos de equações, conversões, de dados que se transformaram em um software, constitui um sistema de

pretar. Nos modelos teóricos no melhor das hipóteses "algumas de suas conseqüências comprováveis se mostram aproximadamente verdadeiras" [12, p.28-29].

8 Pesquisa operacional é um termo de origem militar, surgido pela primeira vez na segunda guerra mundial. Inicialmente, uma disciplina desenvolvida para tomada de decisão em estratégias militares. Atualmente é considerada como uma ciência aplicada a várias áreas do conhecimento. De cunho interdisciplinar, vale-se de inúmeras metodologias para a resolução de problemas científicos. $[22]$ substituição ao sistema real, do qual não se tem teoria completa, e que permite fazer experiências fictícias, para compreender o jogo complexo das suas interações. E estas experiências fictícias constituem efetivamente uma metodologia de substituição, em relação ao método hipotético-dedutivo assim como em relação ao método experimental, no caso dos sistemas complexos" [5, p.113].

A partir da segunda guerra mundial o computador deixa de ser uma simples máquina de calcular e passa a desempenhar o papel de uma máquina de reunir uma grande densidade de dados e teorias, tratando de um vasto número de informações que até então eram intratáveis de outra maneira [5]; de forma semelhante, ele nem sempre exerce o papel de intermediário entre teoria e dados empíricos, deixando também de se basear apenas em um sistema formal (aquele empregado em lógica matemática) em busca da delimitação de um sistema físico ou social: "[...] o modelo não é mais apenas uma estrutura matemática que representa uma teoria, ele torna-se uma dupla representação parcial e orientada (pelo objetivo que se tem e pelo estado do sistema de observação e de medida) [...]" [5, p.112-113].

Busca-se a partir de então, através da simulação por software, antecipar o comportamento dos fenômenos para poder inferir sobre eles. Trata-se de uma técnica bastante empregada na pesquisa operacional que reside no "uso do computador para imitar (simular) a operação de um processo ou sistema por inteiro" antes mesmo de testar a sua validade no mundo real [23]. As simulações, imitações ou experiências fictícias são formas de perceber ou inventar uma realidade (ou as supostas realidades) difícil de ser interpretada e conhecida; as técnicas para isso vão desde a "análise de risco em processos financeiros" até ao desenvolvimento de simuladores de vôo para "imitar o desempenho de um avião de verdade em um ambiente controlado" [23, p.1]. Nestes novos métodos de modelagem ou modelização um sistema parece deixar de ser considerado como conjunto de elementos em interação para passar a ser visto como um conjunto complexo de elementos em interação, um "sistema complexo".

Nesse breve cenário histórico e epistemológico tentamos apresentar alguns pontos de vista de filósofos da ciência, cientistas e pesquisadores a respeito da noção de modelo científico nas ciências formais e factuais. Embora seja um cenário preliminar e incipiente, o qual não nos permite retirar todas as consequências históricas e filosó- 
ficas possíveis, vamos nos ater a algumas conclusões mais gerais sobre o conceito de modelo e sobre as possíveis relações entre os modelos e as teorias.

\section{O que é modelo, afinal?}

1) Atualmente, não se pode mais definir de modo "universal" o que é um modelo, como bem lembrou o epistemólogo e desenvolvedor da Teoria dos Sistemas, Jean-Louis Le Moigne [6]. O que é um modelo? Um desenho, um diagrama, um esboço, uma ilustração, um objeto concreto (maquete), uma estrutura matemática (modelo simbólico), um software de computador, uma cópia de alguma coisa (modelo icônico), tudo isso pode ser considerado modelo de algo. Tomados no sentido epistemológico todos podem ser considerados como estruturas concretas ou abstratas que visam de alguma forma representar alguns aspectos de uma determinada realidade - fato ou coisa [12] ou fenômeno [6].

2) Sejam modelos concretos ou abstratos, tangíveis ou intangíveis, visualizáveis ou inteligíveis, icônicos ou simbólicos o que os define como bons ou maus modelos é a estrutura teórica que carregam, ou o seu modelo teórico. Pode-se dizer então que um modelo não tem tanto valor em si mesmo, se não naquilo que ele faz e para aquilo que ele serve [13, p. 294]. Parece que mais importante do que encontrar uma única e precisa definição para a polissêmica palavra "modelo" é procurar por sua funcionalidade. Contribuições da epistemologia Bungeana nos permitiram entender que os modelos (objetos-modelo) funcionam como "pontes" de ligação entre as teorias e a realidade, operando algumas vezes como instrumentos de validação empírica de uma teoria, e em outras vezes dando origem a novos objetos-modelo e a novas teorias [12].

3) Os modelos científicos são entendidos como idealizações da realidade e não a própria realidade. No máximo alguns de seus aspectos, alguns de seus referentes são por ele representados. Sendo assim, sempre existirão elementos da realidade que escapam ao modelo e a sua teoria subjacente.

4) Os modelos científicos apresentam limites de representatividade e, sejam eles concretos ou abstratos, o que os define como bons ou maus modelos são os seus modelos teóricos ou as teorias específicas que carregam [12]. Não se pretende aqui esgotar as (muitas) acepções do que seria uma "teoria científica". De todo modo, é possível produzir um pequeno inventário dessas acepções, sempre mantendo o foco no objeto desse trabalho, os modelos.

Inicialmente, pode-se dizer que teorias, necessariamente, produzem afirmações, passíveis de confirmação ou falseamento. Duhem, já em 1914 [24], asseverava que as teorias poderiam ser caracterizadas por quatro operações sucessivas: 1- a determinação quantitativa das grandezas pertinentes, 2- a escolha judiciosa das hipóteses, 3- o desenvolvimento lógico - dedutivo dessas hipóteses e 4- confrontações das previsões da teoria com a experiência. Numa acepção um tanto mais moderna, pode-se estipular que teorias científicas contém axiomas, teoremas, demonstrações e definições. Mas é importante pontuar que o conteúdo dessas teorias é necessariamente conexo, uma teoria merece justamente esse nome por configurar um todo estruturado e articulado, e na consecução de tal fim é feito o uso de uma linguagem que não encontra necessariamente contrapartida na observação direta. Nesse sentido, Rosenberg [25] postula que "[uma] teoria é um conjunto de hipóteses que alegam que conjuntos particulares de coisas no mundo são satisfeitos em diversos graus por um conjunto de modelos que refletem alguma similaridade ou unidade."

Retomando então a posição anterior, (modelos são bons ou maus dependendo das teorias específicas que carregam) é possível olharmos para outra direção, conforme já haviam sugerido os precursores da inteligência artificial, Simon e Newell [26] e considerar que as teorias científicas também cometem os mesmos pecados. Isto é, uma teoria científica, entendida como um "conjunto de afirmações ou sentenças declarativas" sejam elas matemáticas ou verbais que visam expressar através do seu conteúdo lógico a verdade sobre os fenômenos, pecam por erros de "omissão" e de "comissão". Nos erros do primeiro tipo as teorias não falam toda a verdade sobre a realidade dos fenômenos, elas sempre omitem alguma coisa; nas do segundo tipo, da mesma forma, elas dizem coisas que não encontram contrapartida nessa realidade, elas pecam por excesso:

\begin{abstract}
"A mais conspícua inadequação das teorias é que elas não contam toda a verdade; elas possuem um conteúdo muito menor que o dos fenômenos. Emprestando um termo da estatística, podemos chamar esses erros de omissão de "erros do tipo I". Mas penso que pode ser mostrado que praticamente todas as teorias erram também na outra direção elas dizem coisas que não são, como também falham em dizer coisas que são. Podemos chamar esses erros de comissão de "erros do tipo II". Na medida em que as teorias cometem erros do tipo II - afirmando algumas coisas além da verdade - elas possuem, por certo, um conteúdo total maior que o dos fenômenos" [26, p.68].
\end{abstract}

Os cientistas [26] entendem que as teorias científicas são compostas por um "conteúdo lógico" e um "conteúdo psicológico". Por conteúdo lógico eles se referem "aos fatos que podem ser extraídos dela [da teoria] através da aplicação das leis da lógica”. E por conteúdo psicológico, "as proposições empíricas que o cientista é de fato capaz de derivar dela" [26, p. 68-9]. Ambos os conteúdos são de grande valor para o cientista, porém o conteúdo psicológico é o que pode lhe dar acesso às afirmações da 
teoria em relação aos fato: 99 E, percebendo que as teorias científicas não dizem toda a verdade sobre os fenômenos, os autores completam exortando os cientistas a sempre procurar detectar e evitar erros de omissão e comissão.

Para finalizar, a pergunta que nos cabe fazer então: por que os cientistas não abrem mão dos modelos em suas atividades?

Uma resposta surpreendentemente pertinente pode ser a seguinte: simplesmente por que os modelos, de modo geral, permitem um acesso ao conteúdo psicológico da teoria! Outra resposta cabível: os modelos enquanto idealizações da realidade podem ser entendidos como potentes formas de representação do conhecimento. Ainda nessa mesma perspectiva, e concordando com Suzanne Bachelard (1983) [6, p.3] diríamos ainda: "O modelo é um intermediário a quem delegamos a função de conhecimento", ou seja, ele é um instrumento que nos permite conhecer algo da realidade. Ou ainda, "[...] muitas vezes são construídos modelos porque a teoria completa [ou geral] seria algo muito complexo com o que trabalhar; assim, são introduzidas idealizações que permitem ao cientista produzir resultados significativos com recursos limitados" [27]. Nesse sentido, são os modelos que permitem inferir diretamente sobre os fenômenos e assim testar a plausibilidade, a veracidade da teoria geral em relação à realidade.

Os modelos científicos, enquanto simplificações e idealizações da realidade, são verdadeiras criações do pensamento, e como tal são necessariamente instrumentos falhos numa certa medida, são recursivos, são de fato meios para o conhecimento e embora não seja possível ficar sem eles, também não é desejável a eles se submeter de forma irrestrita [5].

Parece-nos, por fim, interessante fazer a seguinte reflexão: na educação básica o conceito de modelo tem sido objeto de estudo? A relação entre os modelos científicos e os modelos didáticos bem como as suas relações com as teorias é conhecida pelos alunos? Os paradigmas nos quais os modelos estão servidos, a realidade que se procura conhecer são apenas alguns exemplos de questões importantes que poderiam estar no foco das investigações em sala de aula.

Acreditamos que as contribuições sobre a noção de modelo aqui expostas e suas utilizações na ciência são de fundamental importância e poderiam ser mais bem explorados na escola. Algumas experiências práticas de modelização [2][3][4] vem tentando demonstrar essa transposição dos modelos científicos (mais complexos pelo seu conteúdo lógico) para os modelos didáticos, que por sua vez aparecem como representações com um menor nível

\footnotetext{
9 "O conteúdo lógico de uma teoria é utilizável [...] apenas na medida que [se] possa tornar esse conteúdo explícito por meio de manipulações da teoria, tal como colocada. Toda a matemática (e a lógica verbal, na medida em que é rigorosa) é uma grande tautologia. A surpresa que é ocasionada pelo teorema de Pitágoras deriva das propriedades psicológicas da matemática - da nova informação obtida ao processar as afirmações explícitas da teoria matemática - não de sua lógica" [26, p. 69].
}

de abstração, com uma linguagem mais comum, mais próxima da linguagem dos alunos. O modelo didático surge então como resultado da transposição didática dos modelos científicos os quais tentam representar uma parcela lógica da realidade em estudo. Resumidamente o modelo didático se coloca a representar de forma psicológica a parte lógica dos modelos científicos. Seu papel vai além de representar alguns aspectos dos fatos ou fenômenos em estudo, ele também visa oportunizar um aproximado conhecimento da realidade.

\section{Agradecimentos}

Os autores agradecem aos revisores da RBEF pelas valiosas sugestões oferecidas.

\section{Referências}

[1] J.F. Mora, Dicionário de filosofia (Martins Fontes, São Paulo, 2001).

[2] A. Adúriz-Bravo e L. Morales, Caderno Catarinense de Ensino de Física 19, 76 (2002).

[3] F.S. Silva, O. Giovannini e F. Catelli, Caderno Catarinense de Ensino de Física 27, 7 (2010).

[4] F. Catelli, O. Giovannini e F.S. Silva, Caderno Catarinense de Ensino de Física 30, 131 (2013).

[5] M. Armatte, Mathématiques et Sciences Humaines 43, 91 (2005).

[6] http://archive.mcxapc.org/docs/ateliers/lemoign2.pdf.

[7] M. Louâpre, Avant-propos 138, 5 (2007).

[8] J.L. Le Moigne, A Teoria do sistema geral: teoria da modelização (Instituto Piaget, Lisboa, 1977), p.23.

[9] S.R. Dahmen, Revista Gazeta da Física 30, 22 (2007).

[10] T. Roque e A.A.P. Videira, Scientiae Studia 11, 281 (2013).

[11] L.H.A. Dutra, Scientiae Studia 3, 210 (2005).

[12] M. Bunge, Teoria e Realidade (Editora Perspectiva, São Paulo, 1974).

[13] M. Armatte e A.D. Dalmedico, Revue d'histoire des sciences 57, 244 (2004).

[14] J.F. Carvalho, Ciência e Cultura 64, 52 (2012).

[15] L.H.A. Dutra, Philósophos: revista de filosofia 11, 252 (2006)

[16] C.B. Boyer, História da Matemática (Edgard Blücher, São Paulo, 1996), p. 435.

[17] M.I.A. Chaves e A.O. Espírito Santo, Um modelo de modelagem matemática para o Ensino Médio, In: Anais do VII Congresso Norte/Nordeste de Educação em Ciências e Matemática, Belém, 8 a 11de dez. 2004.

[18] M.S. Biembengut, Modelagem matemática \& implicações no ensino e aprendizagem de matemática (Furb, Blumenau, 1999), p.20.

[19] A. Kaplan, A conduta na pesquisa: metodologia para as ciências do comportamento (Herder, São Paulo, 1972), p. 12.

[20] M. Pietrocola, Investigações em ensino de ciências 4, 15 (1999).

[21] J.F. Custódio e M. Pietrocola, Ciência \& Educação 10, 3 (2004). 
[22] A.Ellenrieder, Pesquisa operacional (Almeida NevesEditores, Rio de Janeiro, 1971).

[23] F.S. Hillier e G.J. Lieberman, Introdução à Pesquisa Operacional (Artmed, São Paulo, 2006) p. 1.

[24] P. Duhem, The aim and structure of physical theory (Atheneum, New York, 1962).

[25] A. Rosenberg, Introdução à Filosofia da Ciência (Loyola, Rio de Janeiro, 2005) p. 133.

[26] H.A. Simon e A. Newell, Models: their uses and limitations, disponível em http: //digitalcollections.library.cmu.edu/awweb/ awarchive type $=$ file\&item $=356856$.

[27] S. French, Ciencia: conceitos-chave em filosofia (Artmed, Porto Alegre, 2009) p. 44 